\title{
PENGEMBANGAN SISTEM INFORMASI KESEHATAN DEMAM BERDARAH DENGUE DENGAN DETEKSI DINI DI KABUPATEN BANDUNG
}

\author{
Wawan Ridwan ${ }^{*}$, Andri Ruliansyah ${ }^{1}$, Firda Yanuarr $^{1}$, Asep Jajang ${ }^{1}$ \\ ${ }^{1}$ Loka Penelitian dan Pengembangan Kesehatan Pangandaran \\ JI. Raya Pangandaran KM. 3 Pangandaran, 46596, Kabupaten Pangandaran, Jawa Barat, Indonesia
}

\begin{abstract}
Dengue Hemorrhagic Fever (DHF) has been identifying as a health problem in Indonesia since 1968 and there was an increasing of morbidity in some areas. The trend of DHF cases and deaths was varied in Bandung Regency during a period of 2012 to 2016. In 2012, there were 1,124 cases with 11 deaths and peaked in 2016 with 3,470 cases and 10 deaths. There's so many factor involving number of dengue cases. One of the obstacles is the lack of early warning systems against outbreaks of DHF. This study was aimed to develop health information systems that can expedite the processing of data and can detect dengue outbreak. The study was conducted using qualitative approach design prototyping models to build models of health information systems. Data has been collected from Bandung District Health Office and prototype design of DHF health information systems with early detection of outbreaks was developed in the same institution. The results of this study indicated that this used system is still manual entry and the developed health information systems can be applied perfectly. This study successfully constructed the concept of health information systems that can speed-up data entry to detect outbreaks of dengue. The developed Health Information System can be applied in all Health Offices in peripheral level to speed up data recording and reporting and also detect outbreaks of DHF earlier.
\end{abstract}

Keywords: Health information systems, dengue haemorrhagic fever.

\section{DEVELOPMENT OF HEALTH INFORMATION SYSTEM FOR EARLY DETECTION OF DENGUE HAEMORRHAGIC FEVER IN BANDUNG REGENCY}

\begin{abstract}
Abstrak
Demam Berdarah Dengue (DBD) diketahui merupakan masalah kesehatan di Indonesia sejak tahun 1968 dan terjadi peningkatan kematian di beberapa daerah. Tren kasus dan angka kematian bervariasi di Kabupaten Bandung selama periode tahun 2012-2016. Pada tahun 2012 ada 1.124 kasus dengan 11 kematian dan meningkat pada 2016 dengan 3.470 kasus dan 10 kematian. Salah satu penyebab peningkatan ini adalah minimnya sistem deteksi dini untuk mencegah wabah DBD. Penelitian ini bertujuan untuk membangun sistem informasi kesehatan yang dapat mempercepat pengolahan data dan bisa mendeteksi KLB DBD. Penelitian dilakukan menggunakan desain kualitatif dengan menerapkan pendekatan model prototyping untuk membangun model sistem informasi kesehatan. Data didapatkan dari Dinas Kesehatan Kabupaten Bandung dan desain prototipe dari sistem informasi kesehatan penyakit DBD dengan deteksi dini KLB DBD dilakukan di institusi yang sama. Hasil dari penelitian ini menunjukan bahwa sistem yang digunakan selama ini masih menggunakan entri manual dan pembangunan sistem informasi kesehatan bisa diterapkan dengan sempurna. Penelitian ini berhasil membangun konsep sistem informasi kesehatan yang bisa mempercepat entri data untuk mendeteksi KLB DBD. Sistem Informasi Kesehatan yang sedang dikembangkan ini bisa diterapkan di semua Dinas Kesehatan seluruh Indonesia untuk mempercepat pengolahan data DBD juga mendeteksi KLB DBD lebih dini.
\end{abstract}


Kata Kunci: Sistem informasi kesehatan, demam berdarah dengue.

Naskah masuk: 3 September 2019; Review: 22 Januari 2020, Layak terbit: 8 April 2020

*Alamat korespondensi penulis pertama: e-mail: kingwawan@gmail.com; Telp: (0265) 7500018

\section{PENDAHULUAN}

Secara global demam berdarah dengue (DBD) menjadi penyakit umum yang menginfeksi manusia. ${ }^{1}$ Penyakit ini merupakan penyakit paling cepat menyebar dengan peningkatan 30 kali lipat dalam insiden global selama 50 tahun terakhir, mempengaruhi lebih dari 100 negara di seluruh wilayah tropis dan subtropis di dunia termasuk Indonesia. ${ }^{2}$ Pada tahun 2017 angka insiden DBD sebesar $22,55 / 100.000$ penduduk dengan persentase kematian sebesar $0,75 \%{ }^{3}$

Peningkatan dan penyebaran kasus DBD tersebut salah satunya disebabkan oleh perkembangan wilayah perkotaan, perubahan iklim, perubahan kepadatan dan distribusi penduduk serta faktor epidemiologi lainnya. ${ }^{4}$

Penderita DBD di Kabupaten Bandung mengalami fluktuasi dari tahun 2012 sampai dengan tahun 2016, tahun 2012 tercatat sebanyak 1.124 kasus dengan kematian sebanyak 11 orang, tahun 2013 tercatat 1.240 kasus dengan kematian sebanyak 7 orang. Pada tahun 2014 tercatat sebanyak 995 kasus dengan kematian sebanyak 4 orang, tahun 2015 tercatat sebanyak 11.013 kasus dengan kematian sebanyak 4 orang, dan tahun 2016 tercatat 3.470 kasus dengan kematian sebanyak 10 orang. ${ }^{5}$

Pola epidemiologi infeksi dengue mengalami perubahan dari tahun ke tahun, jumlah kasus memuncak setiap siklus 10 tahunan. ${ }^{6} \quad$ Faktor-faktor yang mempengaruhi peningkatan dan penyebaran kasus DBD sangat kompleks, antara lain: 1) pertumbuhan penduduk yang tinggi dan cepat; 2) urbanisasi yang tidak terencana dan tidak terkendali; 3) tidak adanya pengendalian vektor nyamuk yang efektif di daerah endemis; serta 4) peningkatan sarana transportasi. ${ }^{6}$

Penyakit DBD bisa menyebabkan wabah dan menyebabkan malapetaka di masyarakat. ${ }^{7}$ Kejadian Luar Biasa (KLB) perlu dideteksi secara dini dan diikuti tindakan yang cepat dan tepat, perlu diidentifikasi adanya ancaman KLB beserta kondisi rentan yang memperbesar risiko terjadinya KLB agar dapat dilakukan peningkatan kewaspadaan dan kesiapsiagaan menghadapi kemungkinan $\mathrm{KLB}$, oleh karena itu perlu diatur dalam pedoman Sistem Kewaspadaan Dini Kejadian Luar Biasa.

KLB DBD dapat dihindari bila sistem kewaspadaan dini (SKD) dan pengendalian vektor dilakukan dengan baik, terpadu, dan berkesinambungan. Peran jumantik dalam memantau jentik di lingkungan memiliki pengaruh yang cukup besar dalam pengembangan sistem kewaspadaan dini. Upaya penanggulangan penyakit demam berdarah sudah sering dilakukan, tetapi upaya tersebut belum mampu mencegah terjadinya wabah demam berdarah. ${ }^{8}$ Seringkali penanganan kasus demam berdarah baru dilakukan setelah jumlah penderita semakin banyak atau ditemukan kasus penderita yang meninggal dunia. ${ }^{9}$

Sistem peringatan dini wabah dan kejadian luar biasa seharusnya dilaksanakan dengan pengawasan pelaksanaan tugas dan wewenang pejabat kesehatan di tingkat pemerintah pusat dan daerah. Agar kewaspadaan dini wabah penyakit menular dapat diandalkan, perlu ada program pengembangan kapasitas (capacity building) dibidang persepsi dan penilaian risiko (risk perception \& risk assessment) wabah penyakit. ${ }^{8}$

Prediksi kejadian DBD di suatu wilayah saat ini dilakukan berdasarkan stratifikasi endemisitas, pola maksimalminimal dan siklus 3-5 tahun sesuai data surveilans epidemiologi. Cara ini memiliki kelemahan karena berubahnya data menjelang musim penularan DBD dan belum adanya data faktor risiko terkini sehingga prediksi sering kurang tepat. ${ }^{10}$ 
Kegiatan surveilans DBD merupakan sebuah proses pengumpulan, pengolahan, analisis dan interpretasi data serta proses penyebarluasan informasi kepada pemegang kebijakan, penyelenggara program kesehatan, dan stakeholder terkait sehingga bisa segera dilakukan tindakan pengendalian yang lebih baik. ${ }^{11}$ Namun saat ini kegiatan surveilans belum terlaksana secara optimal dikarenakan sering terjadi keterlambatan dalam proses pengiriman laporan Kewaspadaan Dini Rumah Sakit (KD-RS) terkait kasus DBD yang terdiagnosa. ${ }^{12}$

Sistem surveilans atau pemantauan wilayah setempat bisa menjadi tapisan pertama untuk deteksi dini terjadinya KLB, maka diperlukan suatu sistem informasi dari awal penanganan penyakit DBD. Awal kejadian penyakit dari mulainya pencatatan dan pelaporan. Penelitian ini dapat mengembangkan suatu sistem informasi kesehatan penyakit DBD yang bisa mendeteksi kejadian luar biasa pada saat data diinput sehingga hasil yang didapatkan menjadi suatu sistem baku pencatatan dan pelaporan penyakit DBD serta sebagai sistem kewaspadaan dini penyakit DBD.

\section{METODE}

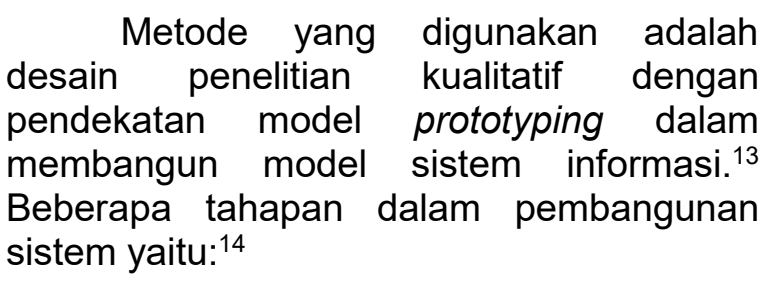

\section{Desain konsep:}

Tahapan dimana analisis sistem informasi kesehatan yang digunakan di tempat penelitian dan sistem bagaimana yang cocok untuk dipakai.

\section{Membangun arsitektur sistem:}

Metode yang digunakan dalam perancangan sistem informasi kesehatan ini adalah metode pengembangan prototyping level 0 hingga level 1 sebagai cetak biru sistem operasional yang akan dikembangkan. ${ }^{14}$ Cara pengumpulan data untuk pengembangan sistem informasi kesehatan dengan data primer dan sekunder yang dilakukan dengan cara melakukan identifikasi kebutuhan user, dalam mengembangkan prototype peneliti akan membuat Design Logic dimana akan diperlihatkan kepada user. ${ }^{15}$ Urutan pembangunan sistem dijabarkan dengan tahapan Flowchart (Bagan Alir) penjabaran sistem informasi kesehatan dalam bentuk bagan alir sangat penting untuk memudahkan posisi masing-masing institusi dalam penanganan laporan sebuah kasus. ${ }^{16}$ Contex Diagram (Diagram Konteks) metoda yang memudahkan pemahaman sebuah model ilmiah sistem informasi. ${ }^{17}$ Entity Relatiton Diagram (ERD) metode untuk menjabarkan entity hubungan antara alur, database dan arah sehingga memudahkan pembuat program untuk membuat sistem informasi. ${ }^{18}$ Data Flow Diagram (DFD) menjelaskan secara ilmiah data dan informasi dalam sistem informasi juga infrastruktur database dan komputerisasi program. ${ }^{19}$

\section{Prototyping:}

Ini adalah tahap dimana bukti dari desain konsep sering digunakan untuk menunjukkan bahwa sistem dapat dibangun berdasarkan hasil dari tahap sebelumnya. ${ }^{20}$

\section{Pengembangan produk:}

Penerapan sistem spesifikasi untuk membangun, menguji, dan mengevaluasi sistem yang kuat. ${ }^{21}$

Pengumpulan data dilakukan melalui observasi langsung, wawancara mendalam menggunakan pedoman wawancara, dan telaah dokumen terkait dengan gambaran sistem pencatatan dan pelaporan program DBD di Dinas Kesehatan Kabupaten Bandung. Lama kegiatan adalah satu tahun yaitu tahun 2014. Pembangunan sistem informasi menggunakan aplikasi Visual Studio 2010 dan Microsoft Access 2007.

\section{HASIL}

\section{Desain Konsep}

Sumber data yang digunakan untuk SIK deteksi dini KLB merupakan data dari puskesmas dan rumah sakit yang dijadikan input baik dalam harian (KLB atau W1), mingguan (W2, DP-DBD dan KD/RS), dan laporan bulanan puskesmas dan rumah sakit, sedangkan proses pembuatan laporan DBD kabupaten maupun deteksi dini KLB terkendala dalam hal ketepatan dan kelengkapan laporan dari puskesmas. 
Tabel 1. Analisa input, proses, dan output

\begin{tabular}{|c|c|}
\hline Var & Permasalahan \\
\hline Input & $\begin{array}{l}\text { a. Laporan W2 (mingguan) dikirim tidak seminggu sekali, tetapi kadang setiap bulan } \\
\text { karena terkendala tenaga dan biaya puskesmas untuk pergi ke Dinas kesehatan } \\
\text { Kabupaten Bandung. } \\
\text { b. Tidak semua rumah sakit mengirimkan laporan KD/RS sehingga pihak dinas kesehatan } \\
\text { harus datang ke RS untuk mengambil laporan tersebut. } \\
\text { c. Luasnya wilayah Kabupaten Bandung menghambat dalam pengiriman laporan yang } \\
\text { cepat sehingga kelengkapan dan ketepatan laporan masih rendah. }\end{array}$ \\
\hline Proses & $\begin{array}{l}\text { a. Tumpang tindih/double entry jumlah penderita dikarenakan ada puskesmas dan rumah } \\
\text { sakit mengirim data yang sama. } \\
\text { b. Butuh SDM tambahan yang dibutuhkan khusus untuk validasi dan entri data. } \\
\text { c. Dikarenakan semua laporan dari puskesmas dan rumah sakit berupa paper base, maka } \\
\text { ada kemungkinan data hilang sebelum dientri. }\end{array}$ \\
\hline Output & $\begin{array}{l}\text { a. Pembuatan laporan mingguan tepat waktu di Dinas Kesehatan Kabupaten Bandung } \\
\text { masih belum bisa dilaksanakan karena kelengkapan dan ketepatan data dari puskesmas } \\
\text { dan rumah sakit masih rendah. } \\
\text { b. Belum bisa melaksanakan perhitungan titik musim penularan } \\
\text { c. Belum bisa melaksanakan perhitungan peningkatan kasus mingguan } \\
\text { d. Belum bisa melaksanakan deteksi dini KLB DBD }\end{array}$ \\
\hline
\end{tabular}

\section{Membangun arsitektur sistem}

Design Logic sistem informasi kesehatan penyakit demam berdarah dengue dengan

deteksi dini kejadian luar biasa bisa dilihat di Gambar 1.

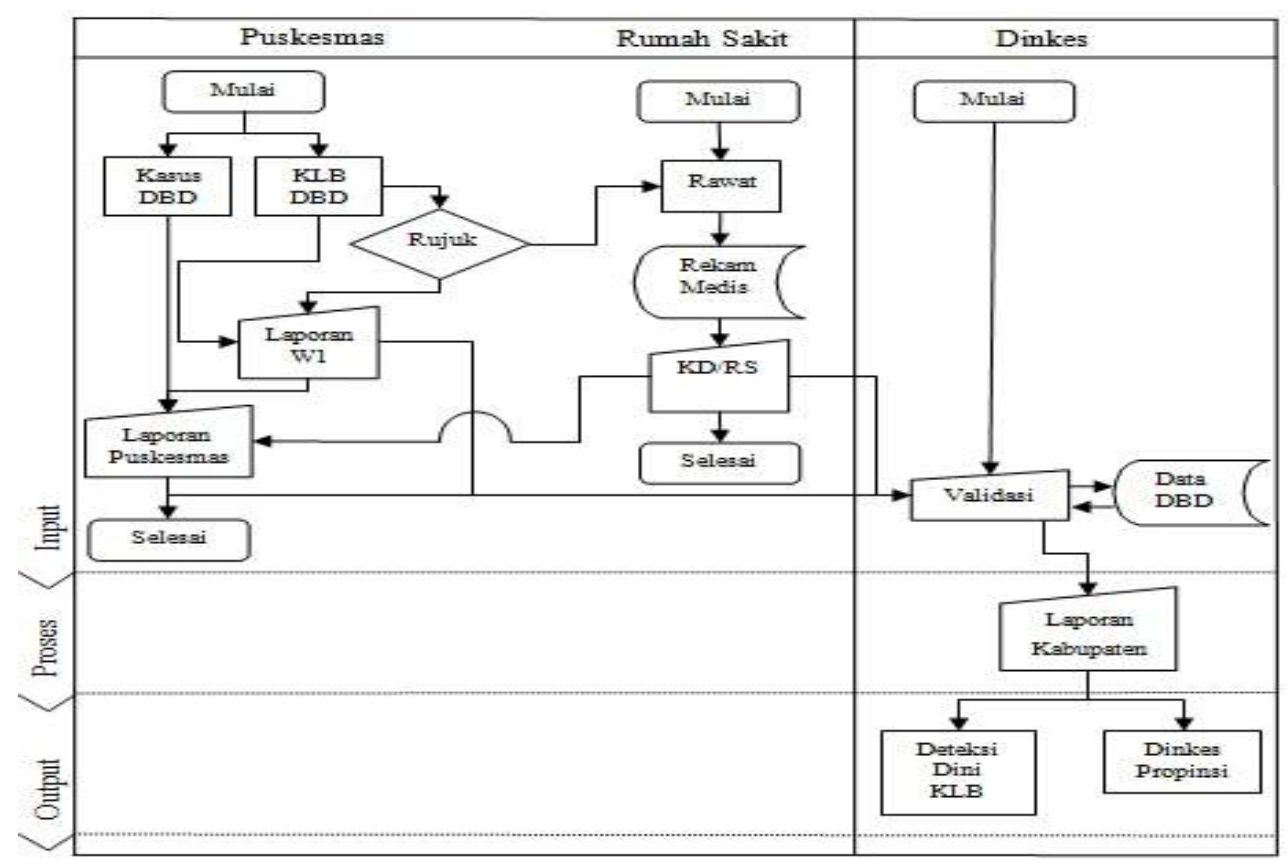

Gambar 1. Bagan alir

Bagan alir seperti gambar 1 menunjukkan alur pencatatan dan pelaporan kasus DBD dari 3 institusi yang terlibat yaitu puskesmas, rumah sakit dan dinas kesehatan, sedangkan posisi sistem informasi kesehatan ini berada di dinas kesehatan baik pada alur proses, alur input, maupun ouput. 


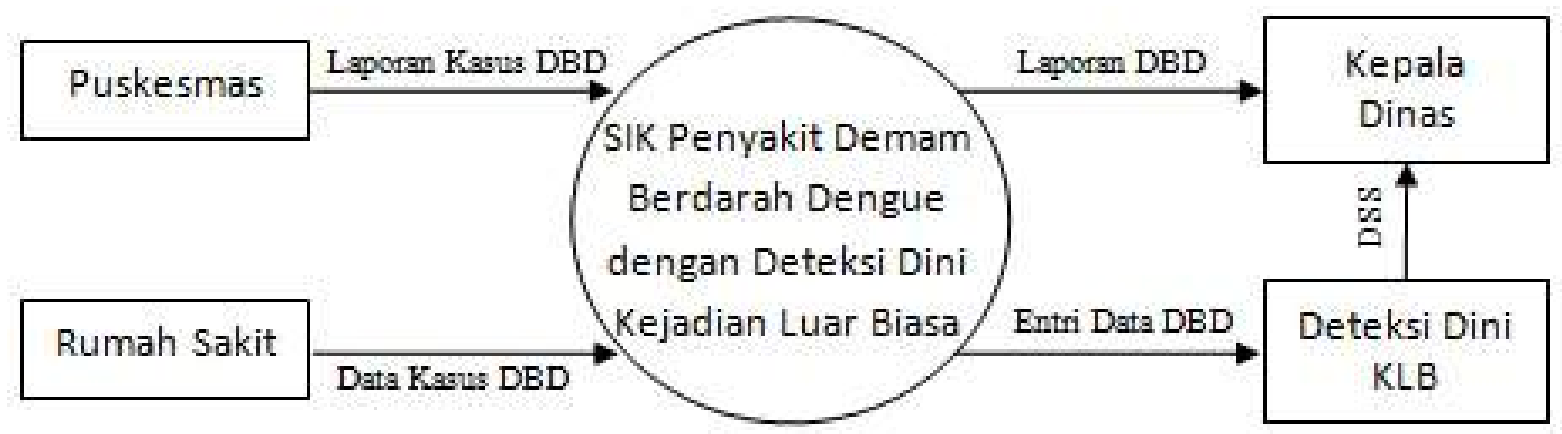

Gambar 2. Diagram konteks

Gambar 2 menunjukkan posisi proses sistem informasi yang dibuat, dimana interaksi antara puskesmas dan rumah sakit sebagai sumber data dan menghasilkan keluaran kepada kepala dinas kesehatan sebagai pembuat kebijakan dalam deteksi dini kejadian luar biasa penyakit.

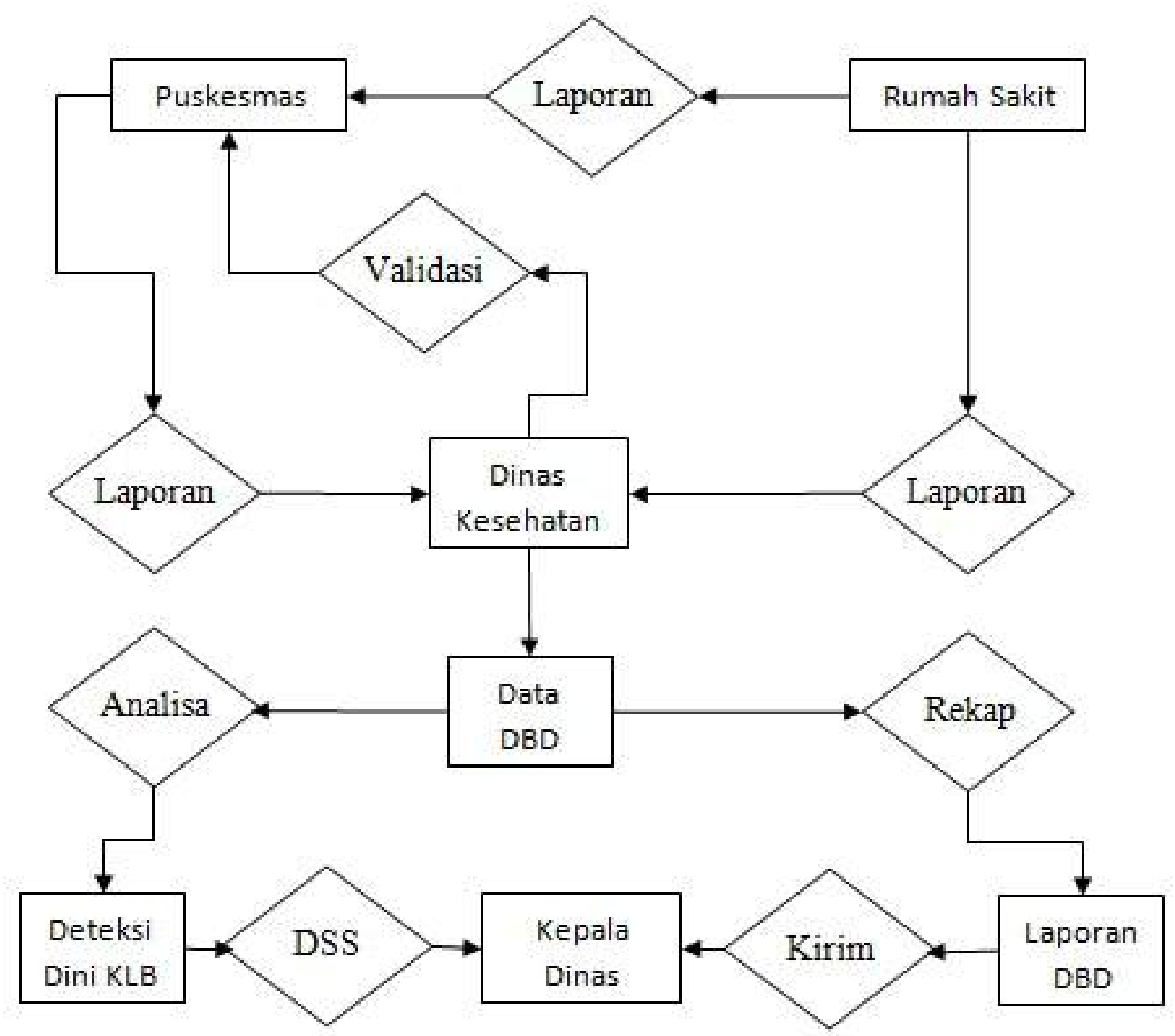

Gambar 3. Entity relatiton diagram

Gambar 3 menjelaskan hubungan dan aliran data kasus DBD dan posisi dimana deteksi dini dalam Decision Suport
System (DSS) atau sistem yang membantu membuat keputusan. 


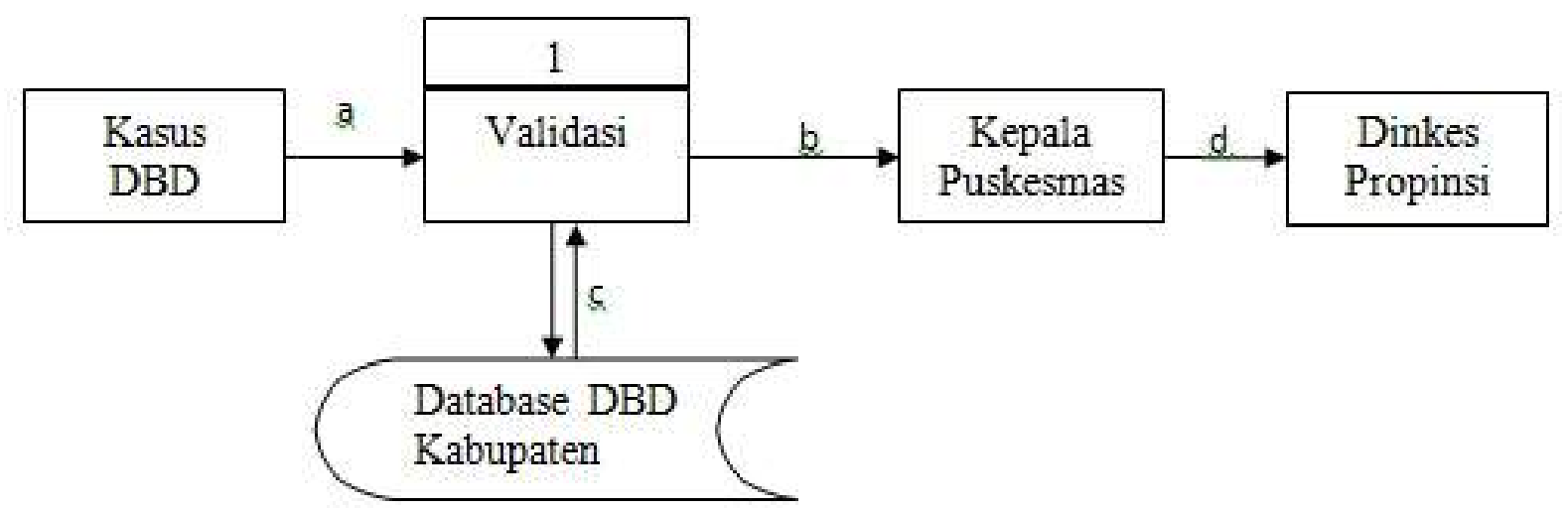

Gambar 4. Data Flow Diagram Level 0

Keterangan :

$a=$ Laporan W1, Laporan W2, DP-DBD, KD/RS

$\mathrm{b}=$ Laporan DBD mingguan, bulanan, triwulanan dan tahunan

c = Tambah, edit dan simpan data DBD

$\mathrm{d}=$ Laporan DBD Kabupaten

Gambar 4 menjelaskan posisi laporan kasus DBD, database dan arah laporan dan jenis laporan yang menjadi keluaran.
Penjelasan lebih rinci dari validasi laporan DBD yang ada di DFD level 0 diperjelas lagi di DFD level 1 pada gambar 5.

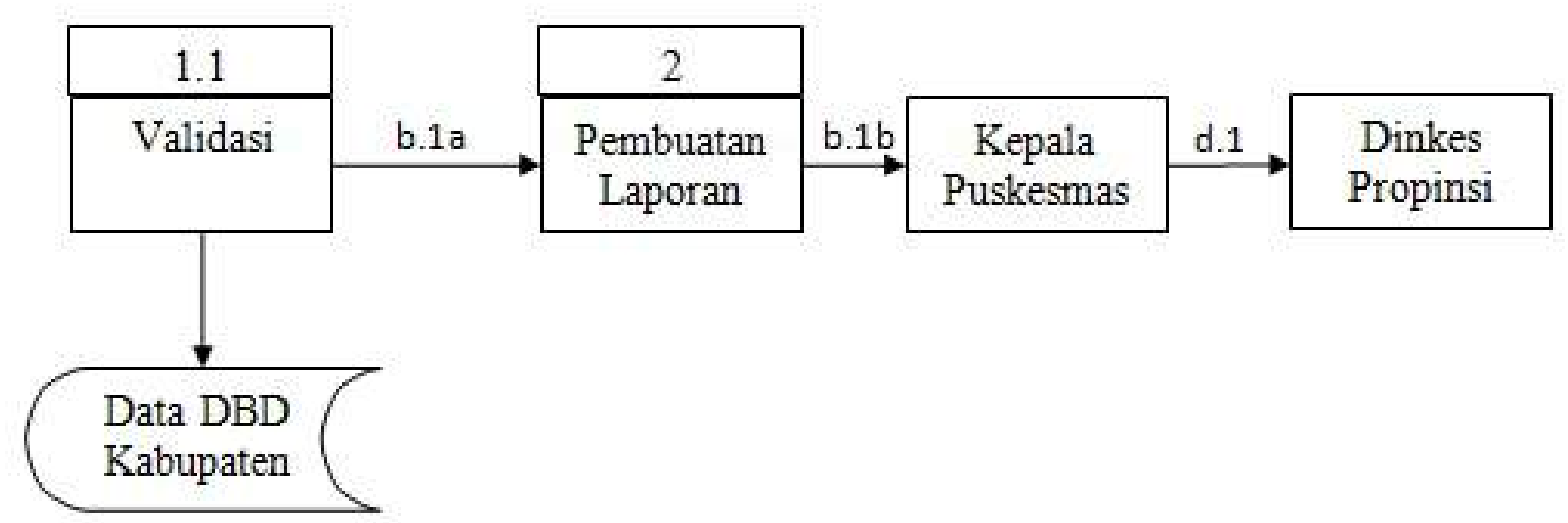

Keterangan :

b.1a = Rekap laporan Puskesmas dan Rumah Sakit

b.1b = Rekapan Laporan DBD

Gambar 5. Data flow diagram level 1

\section{Prototyping}

Perancangan sistem informasi kesehatan penyakit DBD dengan deteksi dini kejadian luar biasa di Kabupaten Bandung dirancang dengan tampilan seperti di Gambar 6 sampai Gambar 18. Menu utama merupakan menu navigasi yang memuat banyak sub menu. Tampilan sub menu pada menu utama, secara rinci dijelaskan pada Gambar 8. 


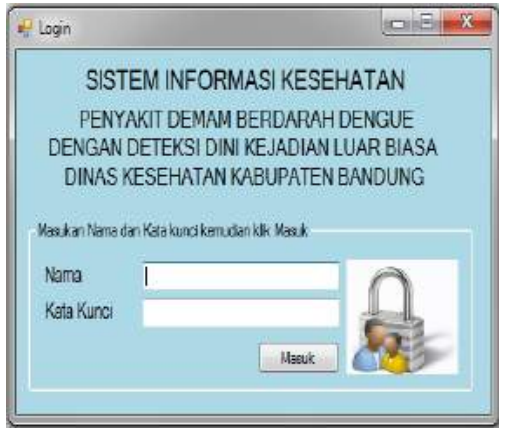

Gambar 6. Menu login

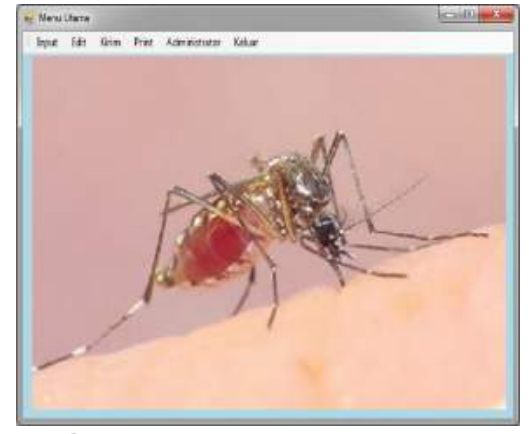

Gambar 7. Menu utama

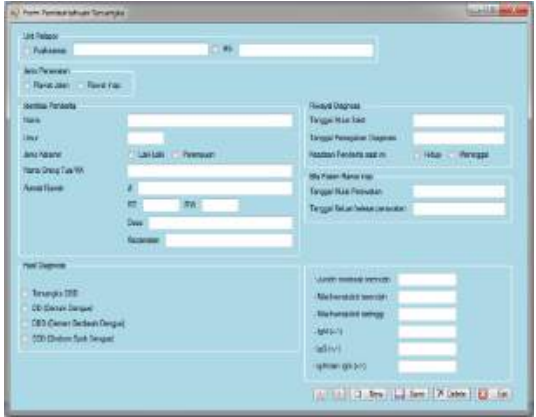

Gambar 8. Formulir pemberitahuan tersangka

Menu ini untuk memasukkan data baik dari puskesmas maupun rumah sakit. Menu ini digunakan untuk memasukkan data

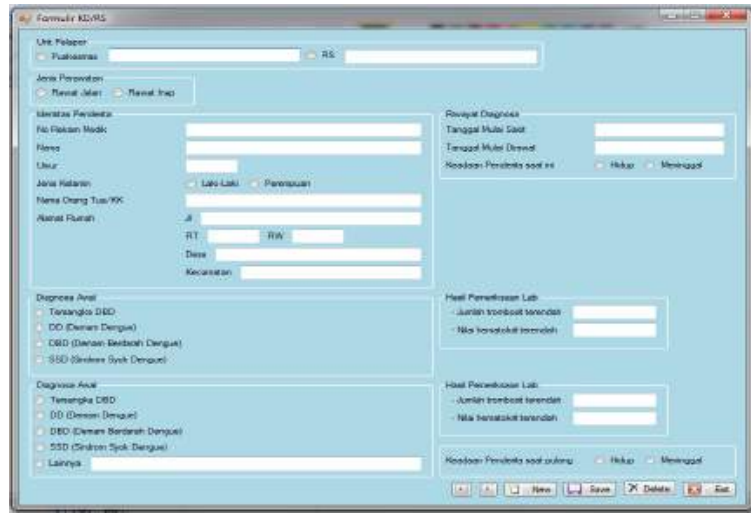

Gambar 9. Formulir KD/RS

Formulir KD/RS merupakan format laporan DBD dari rumah sakit ke dinas kesehatan bisa juga datang dari puskesmas yang mendapat tembusan dari rumah sakit. Formulir DP-DBD adalah formulir rekapan laporan puskesmas dari hasil tembusan KD/RS dari rumah sakit dan KD/RS puskesmas sendiri.

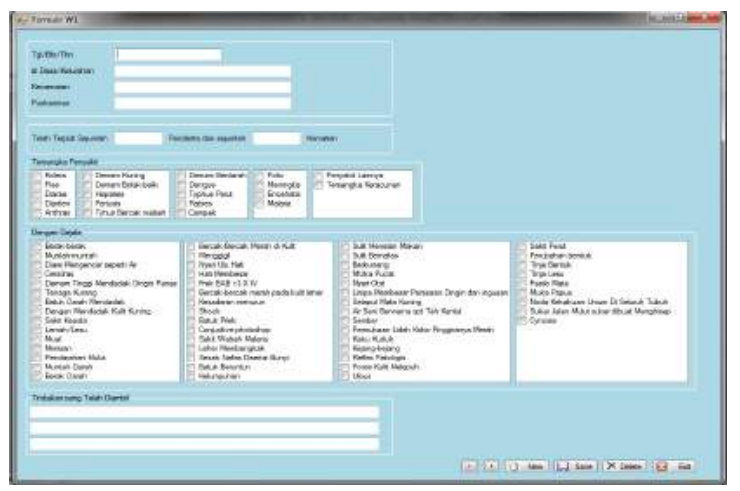

Gambar 11. Formulir W1 tersangka DBD baik dirawat inap maupun rawat jalan dan harus dilaporkan ke dinas kesehatan tidak lebih dari 1 X 24 jam.

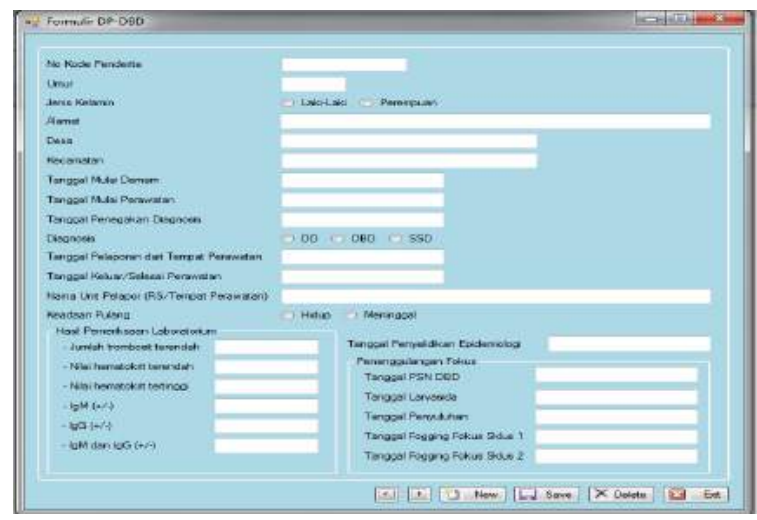

Gambar 10. Formulir DP-DBD

Formulir W1 adalah formulir bila ada kematian akibat penyakit menular termasuk penyakit DBD. Formulir W1 disertakan untuk investigasi penderita dengan kematian atau tanpa kematian dengan gejala-gejala spesifik. Formulir W2 merupakan laporan rekapitulasi mingguan puskesmas yang dilaporkan ke Dinas Kesehatan Kabupaten Bandung.

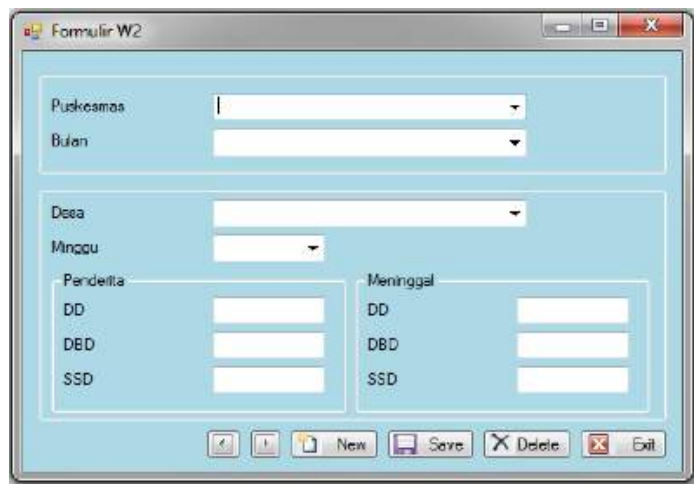

Gambar 12. Formulir W2 


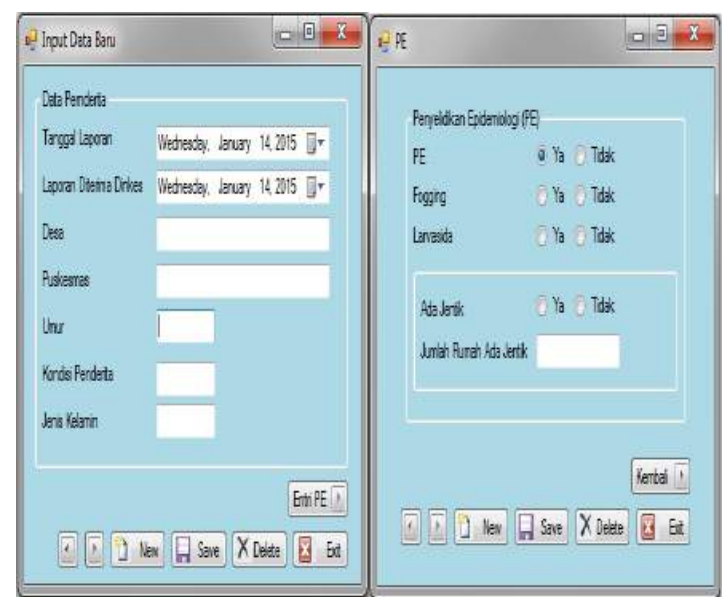

Gambar 13. Input data baru penderita

Formulir pemasukkan data DBD yang dilakukan dinas kesehatan dengan melihat laporan dari puskesmas (Form W2, Form W1, Form DP-DBD dan Form KD/RS) juga dari rumah sakit (Form KD/RS). Menu input dinas kesehatan ada 2 yaitu menu data penderita baru dan input penyelidikan epidemiologi.

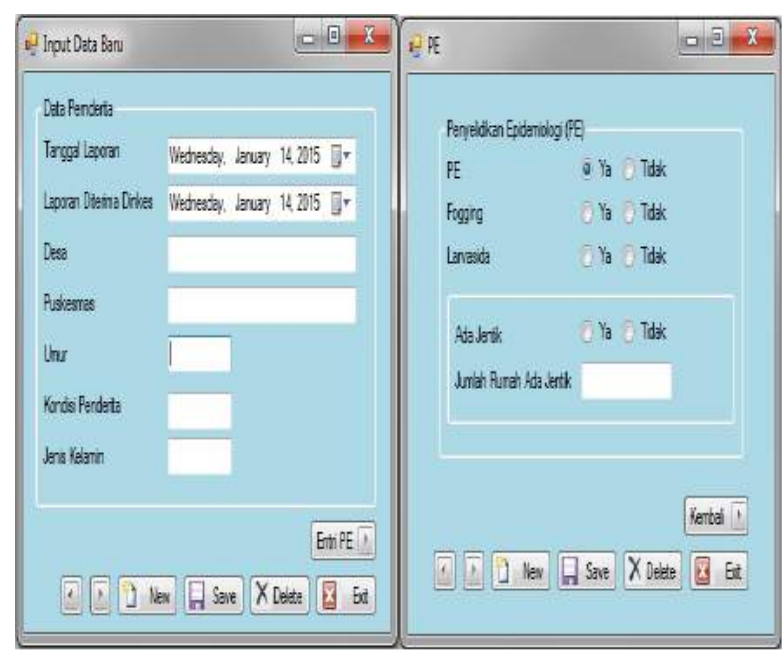

Gambar 14. Input penyelidikan epidemiologi

Menu edit digunakan untuk mengubah data yang telah dimasukkan ke database dinas kesehatan. Oleh karena database asli dari lapangan belum tersedia, kami membuat dari contoh salah satu database untuk disimulasikan dari mulai entri sampai keluar output

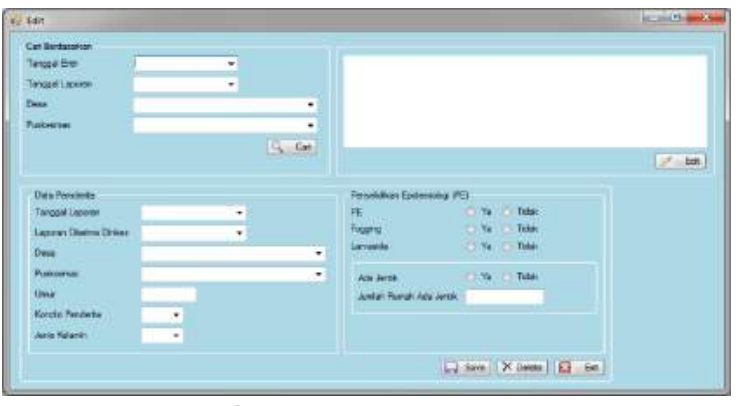

Gambar 15. Edit

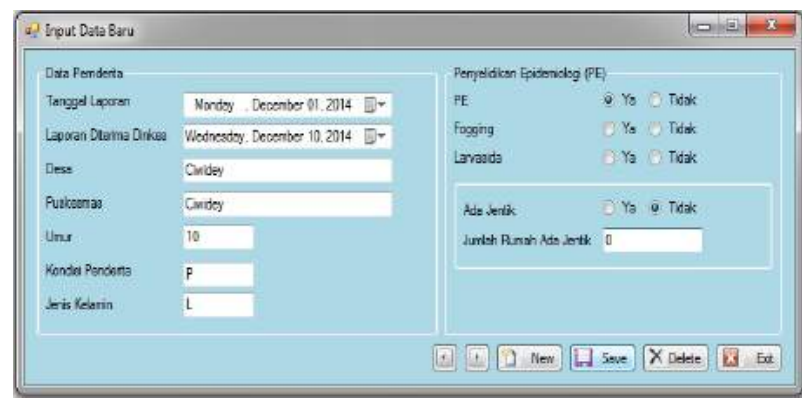

Gambar 16. Output (simulasi input data) 


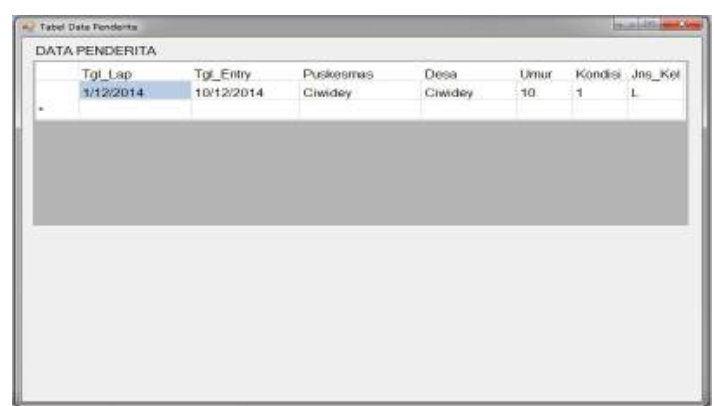

Gambar 17. Output (tabel data penderita)

Karena database kasus DBD Kabupaten Bandung masih kosong,maka belum terlihat ada peringatan. Jika database sudah terisi dan sistem perhitungan deteksi KLB DBD berjalan dengan baik maka bila diklik tombol save akan keluar menu Pop-Up berupa peringatan.

\section{Pengembangan Produk}

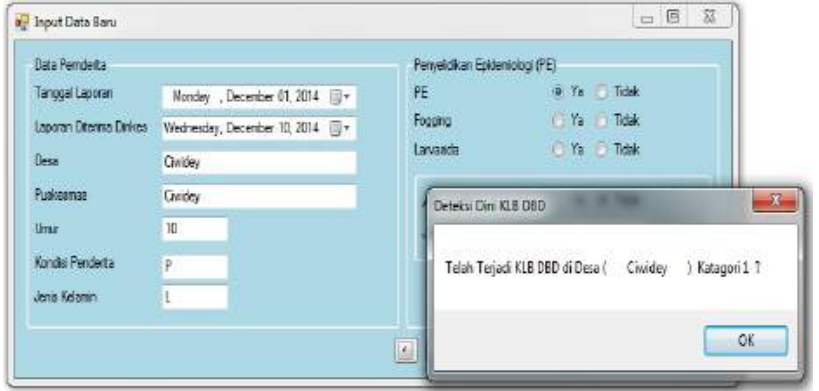

Gambar 18. Output (simulasi deteksi dini KLB)

Tabel 2. Permasalahan dan solusi program DBD di Dinas Kesehatan Kabupaten Bandung

\begin{tabular}{|c|c|c|}
\hline & Permasalahan & Solusi \\
\hline & $\begin{array}{l}\text { a. Laporan W2 (mingguan) tidak dikirim seminggu } \\
\text { sekali, tetapi kadang setiap bulan karena } \\
\text { terkendala tenaga dan biaya petugas puskesmas } \\
\text { untuk pergi ke Dinas Kesehatan Kabupaten } \\
\text { Bandung } \\
\text { b. Tidak semua rumah sakit mengirimkan laporan } \\
\text { KD/RS sehingga harus pihak dinas kesehatan } \\
\text { harus mendatangi rumah sakit untuk mengambil } \\
\text { data kasus } \\
\text { c. Wilayah Kabupaten Bandung yang luas menjadi } \\
\text { salah satu faktor penghambat dalam pengiriman } \\
\text { laporan yang cepat sehingga kelengkapan dan } \\
\text { ketepatan laporan masih rendah }\end{array}$ & $\begin{array}{l}\text { Dibutuhkan persamaan persepsi } \\
\text { dari semua institusi yang terlibat } \\
\text { baik puskesmas, rumah sakit dan } \\
\text { dinas kesehatan dalam bentuk } \\
\text { suatu pertemuan lintas sektor } \\
\text { dimana semua hadir dan sepakat } \\
\text { untuk membuat solusi terbaik dalam } \\
\text { menyediakan kelengkapan dan } \\
\text { kecepatan laporan DBD dan } \\
\text { penyediaan dana sehingga bisa } \\
\text { meminimalkan hambatan laporan } \\
\text { yang masuk ke dinas kesehatan. }\end{array}$ \\
\hline $\begin{array}{l}\mathrm{P} \\
\mathrm{r} \\
\mathrm{o} \\
\mathrm{s} \\
\mathrm{e} \\
\mathrm{s}\end{array}$ & $\begin{array}{l}\text { a. Tumpang tindih/double entry jumlah penderita } \\
\text { dikarenakan ada puskesmas dan rumah sakit } \\
\text { mengirim data yang sama. } \\
\text { b. Butuh SDM tambahan yang dibutuhkan khusus } \\
\text { untuk validasi dan entri data. } \\
\text { c. Dikarenakan semua laporan dari puskesmas dan } \\
\text { rumah sakit berupa paper base, maka ada } \\
\text { kemungkinan data hilang sebelum diinput kedalam } \\
\text { aplikasi. }\end{array}$ & $\begin{array}{l}\text { Dinas kesehatan membutuhkan } \\
\text { pengadaan sarana dan prasarana } \\
\text { maupun tenaga khusus dan } \\
\text { ruangan khusus untuk validasi data } \\
\text { dan penyimpanan arsip laporan } \\
\text { yang masuk. }\end{array}$ \\
\hline $\begin{array}{l}\text { O } \\
u \\
t \\
p \\
u \\
t\end{array}$ & $\begin{array}{l}\text { a. Pembuatan laporan mingguan tepat waktu di Dinas } \\
\text { Kesehatan Kabupaten Bandung masih belum bisa } \\
\text { dilaksanakan karena kelengkapan dan ketepatan } \\
\text { data dari puskesmas dan rumah sakit masih } \\
\text { rendah. } \\
\text { b. Belum bisa melaksanakan perhitungan titik musim } \\
\text { penularan. } \\
\text { c. Belum bisa melaksanakan perhitungan } \\
\text { peningkatan kasus mingguan. } \\
\text { d. Belum bisa melaksanakan deteksi dini KLB DBD. }\end{array}$ & $\begin{array}{l}\text { Implementasi Aplikasi Sistem } \\
\text { Informasi Kesehatan Penyakit DBD } \\
\text { dengan Deteksi Dini KLB DBD }\end{array}$ \\
\hline
\end{tabular}


Sistem Informasi Kesehatan Penyakit DBD dengan Deteksi Dini KLB didesain untuk menghasilkan data dan informasi tentang program DBD dengan menyertakan secara otomatis deteksi dini KLB DBD, sistem ini mempunyai kelebihan dan kekurangan dari pencatatan dan pelaporan program DBD yang selama ini digunakan. Adapun kelebihan dan kekurangan tersebut bisa dilihat pada tabel dibawah.

Tabel 3. Kelebihan dan kekurangan sistem informasi kesehatan penyakit DBD dengan deteksi dini KLB

Kelebihan
Kekurangan
1. Dapat mempercepat proses pengolahan data menjadi informasi yang dibutuhkan.

2. Adanya sistem basis data yang dapat membantu petugas dalam penyimpanan data yang lebih terstruktur sehingga pemanggilan data kembali dapat lebih mudah.

3. Informasi yang disajikan dalam bentuk tabel dan grafik sehingga dapat menggambarkan tren DBD.

4. Mempermudah penelusuran data serta menghasilkan informasi yang lebih cepat dan akurat.

5. Dapat mendeteksi KLB DBD pada saat entri data.

6. Dapat dikembangkan lebih lanjut entri secara online dan entri bisa dilaksanakan di puskesmas.

\section{BAHASAN}

Prediksi kejadian DBD di suatu wilayah selama ini dilakukan berdasarkan stratifikasi endemisitas, pola maksimalminimal, dan siklus 3-5 tahun sesuai dari data surveilans epidemiologi. ${ }^{22,23}$ Cara ini memiliki kelemahan karena berubahnya data menjelang musim penularan DBD dan belum adanya data faktor risiko terkini sehingga prediksi sering tidak tepat. ${ }^{10}$ Bila prediksi siklus tahunan DBD bisa dilakukan dengan tepat, maka kejadian DBD bisa diramalkan setiap 5 tahun. ${ }^{24}$

KLB DBD dapat dihindari bila sistem kewaspadaan dini (SKD) dan pengendalian vektor dilakukan dengan baik, terpadu, dan berkesinambungan. ${ }^{25,26}$ Peran jumantik juga ikut mempengaruhi terlaksananya SKD ini. Hasil penelitian di Semarang menunjukkan bahwa usia dan sikap jumantik mempengaruhi sistem kewaspadaan dini DBD, selain itu dukungan dari petugas puskesmas dan kelurahan juga ikut mempengaruhi sistem kewaspadaan dini DBD. ${ }^{27}$

Pembentukan grup pemantau jentik yang beranggotakan remaja dengan nama MAWAS DBD terbukti berhasil menurunkan jumlah rumah positif jentik.
Kegiatan ini membutuhkan dukungan dari orang tua dan supervisor dalam hal ini ketua RT dan ketua RW. Kunjungan yang berulang-ulang disertai penyuluhan diharapkan dapat meningkatkan motivasi masyarakat untuk melakukan PSN DBD secara teratur. ${ }^{28,29}$

Perkembangan teknologi juga mendorong dikembangkannya sistem kewaspadaan dini kejadian DBD. ${ }^{30}$ Diharapkan ada inovasi baru dan tidak lagi hanya mengandalkan jumantik atau petugas puskesmas. Dibutuhkan pengembangan dari sistem yang saat ini sedang berjalan.

Pengembangan ini mengacu pada kebutuhan informasi yang diinginkan oleh pengguna sistem, dalam hal melakukan penanggulangan KLB DBD di wilayah Kabupaten Bandung. Analisis awal sistem informasi kesehatan ini adalah sangat penting dalam proses pengambilan keputusan yang efektif. ${ }^{31}$

Tabel di bawah ini menjelaskan perbedaan antara sistem yang sudah berjalan dengan rancangan sistem yang dikembangkan. Pengguna aplikasi tidak semuanya mempunyai latar belakang pendidikan sistem informasi sehingga ada kesenjangan dalam penerapan aplikasi di masing-masing tempat. Hal ini disebut 
sebagai komunikasi user-desaigner memiliki celah, menyebabkan perbedaan kepentingan tetapi semua kembali kepada tujuan sistem informasi meminimalkan kesulitan dengan pendekatan untuk pemecahan masalah.

Tabel 4. Perbandingan sistem informasi kesehatan penyakit DBD dengan deteksi dini KLB yang sedang berjalan dan yang akan dikembangkan

\begin{tabular}{|c|c|c|}
\hline & \multicolumn{2}{|c|}{ Perbandingan Sistem } \\
\hline & Sistem Lama & Sistem Baru \\
\hline $\begin{array}{l}\text { l } \\
\text { n } \\
\text { p } \\
\text { u }\end{array}$ & $\begin{array}{l}\text { 1.Penumpukan laporan dari puskesmas } \\
\text { tanpa melihat waktu pengiriman data. } \\
\text { 2.Ada kemungkinan double entry data yang } \\
\text { masuk dari puskesmas dan rumah sakit. }\end{array}$ & $\begin{array}{l}\text { 1. Adanya entri waktu laporan dan waktu entri } \\
\text { sehingga ketepatan laporan bisa maksimal. } \\
\text { 2. Analisis ketepatan laporan. }\end{array}$ \\
\hline $\begin{array}{l}P \\
r \\
0 \\
s \\
\text { e } \\
\text { s }\end{array}$ & $\begin{array}{l}\text { 1. Penyimpan data masih di dalam } \\
\text { dokumen, belum ada penyimpanan data } \\
\text { secara sistem basis data. } \\
\text { 2. Pengolahan data dilakukan bila laporan } \\
\text { diterima dan menunggu menumpuk. } \\
\text { 3. Pengolahan data untuk laporan bulanan } \\
\text { menggunakan Ms. Excel. } \\
\text { 4. Data hanya digunakan untuk keperluan } \\
\text { pelaporan. }\end{array}$ & $\begin{array}{l}\text { 1. Sistem data yang dimiliki akan memudahkan } \\
\text { proses penyimpanan dan pengambilan data } \\
\text { untuk pembuatan laporan. } \\
\text { 2. Pengolahan data dilakukan secara otomatis } \\
\text { sehingga data dapat tersedia lebih cepat. } \\
\text { 3. Deteksi Dini KLB DBD dapat diketahui tanpa } \\
\text { harus menunggu laporan lengkap. }\end{array}$ \\
\hline $\begin{array}{l}\text { O } \\
u \\
t \\
p \\
u \\
t\end{array}$ & $\begin{array}{l}\text { Laporan yang dihasilkan hanya sebagai } \\
\text { laporan ke dinas kesehatan propinsi dan } \\
\text { untuk laporan tahunan dinas kesehatan. }\end{array}$ & $\begin{array}{l}\text { 1. Pengeluaran laporan bisa kapan saja } \\
\text { tergantung dibutuhkan. } \\
\text { 2. Adanya output laporan yang lebih tepat dan } \\
\text { lengkap sehingga bisa mendeteksi kinerja } \\
\text { puskesmas. }\end{array}$ \\
\hline
\end{tabular}

Penerapan sistem baru pada awalnya mendapatkan reaksi beragam, adanya keraguan dan ketidak percayaan terhadap keberhasilan sistem pasti akan dirasakan oleh pengguna. Akan tetapi dengan berjalannya waktu secara bertahap keraguan tersebut akan tereliminasi melalui keterlibatan user dalam mencari alternatif dan dalam tahap pelaksanaan proses perubahan, selama tahap pelaksanaan/implementasi, beberapa masalah muncul, tetapi dilakukan koreksi dan penerapan sistem baru meningkatkan proses operasional dan efisiensi entri data. Adaptasi teknologi baru untuk pengguna/penanggung jawab DBD diperlukan. ${ }^{32}$ Hal ini diharapkan mampu menekan biaya bila terjadi KLB dan dapat meningkatan kecepatan pengolahan data. Penerapan sistem sistem yang didukung penuh dan terintegrasi sistem informasi teknologi akan berfungsi sebagai alat strategis dan berkelanjutan. ${ }^{33}$
Sistem Informasi Kesehatan Penyakit DBD dengan Deteksi Dini KLB dapat diimplementasikan secara bertahap disesuaikan dengan kondisi dan kemampuan dinas kesehatan. Pada tahap pertama dapat dikembangkan input hanya untuk dinas kesehatan. Proses input data dilakukan oleh petugas DBD berdasarkan laporan yang masuk dari puskesmas. Proses validasi data dilakukan dengan menganalisis dokumen laporan dari puskesmas secara manual.

\section{KESIMPULAN}

Penanganan laporan kasus DBD di Dinas Kesehatan Kabupaten Bandung diawali dengan paper-based dan tabel sederhana yang butuh waktu baik dalam pengumpulan maupun analisanya. Dengan dibangunnya Sistem Informasi Kesehatan dengan Deteksi Dini KLB DBD ini sudah terbukti mempercepat input, proses sampai output laporan bahkan dapat mendeteksi 
dini KLB sehingga bisa memberikan masukan untuk pemegang kebijakan untuk bertindak cepat dalam penanganan KLB DBD. Sistem informasi ini sudah diterapkan di Dinas Kesehatan Kabupaten Bandung untuk penyempurnaan menuju sistem yang berbasis online. Sistem informasi kesehatan ini bisa diterapkan di semua dinas kesehatan seluruh Indonesia untuk mempercepat pengolahan data.

\section{SARAN}

Sistem informasi kesehatan dapat dikembangkan dalam sistem informasi kesehatan berbasis online atau website realtime untuk mempercepat penanganan KLB DBD di seluruh Indonesia. Keterlambatan penanganan KLB DBD bisa dihilangkan dan pengelolaan penyakit DBD bisa fokus ke preventif dan promotif, tetapi masih dibutuhkan dalam bentuk rekomendasi :

1. Dibuat aturan dari pemerintah daerah yang mendukung perubahan sistem menjadi paperless.

2. Peningkatan sumber daya manusia dari semua aspek pengelola dari tingkat dinas kesehatan sampai puskesmas.

3. Kesiapan sarana dan prasarana untuk menunjang keberhasilan sistem informasi ini.

\section{KONTRIBUSI PENULIS}

Kontribusi penulis pada artikel ini yaitu, WR sebagai kontributor utama berkontribusi terhadap pengumpulan data, penentuan ide penulisan dan analisis data. FY sebagai kontributor utama berkontribusi dalam pembuatan pendahuluan, pembahasan, penarikan kesimpulan dan menyiapkan referensi/daftar pustaka. AR dan AJ sebagai kontributor anggota berkontribusi pada tahap analisis data dan perbaikan bahasa di dalam artikel.

\section{UCAPAN TERIMA KASIH}

Penulis mengucapkan terima kasih
kepada Badan Pengembangan dan Pemberdayaan Sumber Daya Manusia, Universitas Indonesia Fakultas Kesehatan Masyarakat Departemen Biostatistik dan Kependudukan, Dinas Kesehatan Kabupaten, Dr. Drs. Sutanto Priyo H, M.Kes,
R.Sutiawan, S.Kom, MSi dan Arnaningsih Susilowati, SKM Tidak lupa juga penulis ucapkan terima kasih kepada rekan-rekan anggota tim penelitian atas kerjasamanya dan juga para responden penelitian ini.

\section{DAFTAR PUSTAKA}

1. Samanta J, Sharma V. Dengue and its effects on liver. World $\mathrm{J}$ Clin Cases. 2015;3(2):125.

2. WHO. Dengue and Severe Dengue. WHO Fact Sheet. Geneva; 2014.

3. Kemenkes RI. Profil Kesehatan Indonesia 2017. Kurniawan R, Hardhana B, Yudianto, editors. Jakarta: Kementerian Kesehatan RI; 2018. 100 p.

4. Zumaroh. Evaluasi Pelaksanaan Surveilans Kasus Demam Berdarah Dengue di Puskesmas Putat Jaya Berdasarkan Atribut Surveilans. J Berk Epidemiol. 2015;3(1):82-94.

5. Dinkes Kabupaten Bandung. Profil Kesehatan Kabupaten Bandung Tahun 2016. Soreang; 2017.

6. Wowor R. Pengaruh kesehatan lingkungan terhadap perubahan epidemiologi demam berdarah di Indonesia. J e-Clinic. 2017;5(2):10513.

7. Kemenkes RI. Peraturan Menteri Kesehatan RI No. 1501/Menkes/Per/X/2010 Tentang Jenis Penyakit Menular Tertentu Yang Menimbulkan Wabah. Jakarta; 2010 p. 30.

8. Sinaga SN. Kebijakan Penanggulangan Penyakit Demam Berdarah Di Indonesia. J Res Sains. 2015;1(1):1-7.

9. Nyoto RD, Anra H, Sholva Y. Sistem Tanggap Darurat Demam Berdarah Berbasis Sistem Informasi Geografis Dengan Dukungan Informasi Masyarakat Melalui Perangkat Mobile. In: Seminar Nasional Teknologi Informasi dan Komunikasi "Pemanfaatan Teknologi Informasi untuk Membangun Masyarakat Kreatif dan Inovatif." Yogyakarta: Sentika; 2014.

10. Pascawati NA, Satoto TBT, Wibawa $T$, Frutos $R$, Maguin $S$. Dampak Potensial Perubahan Iklim Terhadap 
Dinamika Penularan Penyakit DBD Di Kota Mataram. Balaba. 2019;15(1):49-60.

11. WHO. Global Strategy for Dengue Prevention and Control 2012-2020. World Heal Organiszation. 2012;43.

12. Hamdani D. Perancangan Sistem Informasi Pelaporan Online KDRS Demam Berdarah di Kota Bandung. Annu Res Semin. 2017;2(1):312-4.

13. Hasan $H$. Information Systems Development as a research method. Australas J Inf Syst. 2004;11(2003):4-13.

14. Shendryk V, Boiko A. Stages of Information System Development in the Process Approach. Procedia Comput Sci. 2015;77:98-103.

15. $\mathrm{Ng} \mathrm{R}$. Intercultural Communication in the Hospitality and Tourism Industry: A Study of Message Design Logic Across Two Cultures Intercultural Communication in the Hospitality and Tourism Industry: A Study of Message Design Logic Across Two Cultures. [thesis] Cornell University; 2017.

16. Suleman ATC, Tinangon JJ, Pontoh W. Analisis Sistem Informasi Akuntansi Persediaan Pelumas. J Ris Akunt Going Concern. 2017;12(1):149-59.

17. Robarts JO, Newell D, Abbott KH. Automated Selection Of Appropriate Information Based On A Computer User's Context. Redmond; US 9,183,306 B2, 2015.

18. Al-masree HK. Extracting Entity Relationship Diagram ( ERD ) From Relational Database Schema. Int J Database Theory Appl. 2015;8(3):15-26.

19. Xiong $\mathrm{H}$, Zhang $\mathrm{H}$, Dong $\mathrm{X}$, Meng $\mathrm{L}$, Zhao W. DFDVis: A Visual Analytics System for Understanding the Semantics of Data Flow Diagram. In: Zou B, Li M, Wang H, Song X, Xie W, Lu Z, editors. Data Science. Singapore: Springer Singapore; 2017. p. 660-73.

20. Mahardika IMP, Yuli NKR, Suparmini NKE. Pengembangan Sistem Informasi Karya Ilmiah Mahasiswa Berbasis Web di Perpustakaan Universitas Pendidikan Ganesha. J
Sains dan Teknol. 2016;5(1):702-15.

21. Herlambang TW, Aknuranda I, Saputra MC. Pengembangan Sistem Informasi Kesehatan Berbasis Web Berdasarkan Model Organisasi Dan Manajemen Kesehatan Primer “ANDAL ." 2018;2(4):1602-10.

22. Titik R, Yudi F, Ermi N, Ardini R, Heni $D$, Asep S, et al. A Qualitative Ecohealth Model of Dengue Fever (DF) in Bandung, Indonesia. Int J Trop Dis. 2018;1(1).

23. Arifin AN. Pemanfaatan Penginderaan Jauh dan Sistem Informasi Geografis untuk Pemetaan Tingkat Kerentanan Wilayah terhadap Penyakit Demam Berdarah Dengue di Kecamatan Blora Kabupaten Blora Ahmad. J Bumi Indones. 2019;8(1).

24. Lowe R, Stewart-lbarra AM, Petrova D, García-Díez M, Borbor-Cordova MJ, Mejía R, et al. Climate services for health: predicting the evolution of the 2016 dengue season in Machala, Ecuador. Lancet Planet Heal. 2017;1(4):e142--e151.

25. Tissera $\mathrm{H}$, Pannila-Hetti $\mathrm{N}$, Samaraweera $P$, Weeraman $J$, Palihawadana $\mathrm{P}$, Amarasinghe $\mathrm{A}$. Sustainable dengue prevention and control through a comprehensive integrated approach: the Sri Lankan perspective. WHO South-East Asia J Public Heal. 5(2):106-12.

26. Hussain-Alkhateeb L, Kroeger A, Olliaro P, Rocklöv J, Sewe MO, Tejeda G, et al. Early warning and response system (EWARS) for dengue outbreaks: Recent advancements towards widespread applications in critical settings. PLoS One. 2018;13(5):1-14.

27. Pangestika TL, Cahyo K, Tirto B, Nugraha P. Faktor-Faktor yang Mempengaruhi Perilaku Jumantik dalam Sistem Kewaspadaan Dini Demam Berdarah Dengue di Kelurahan Sendangmulyo. J Kesehat Masy. 2017;5(5):1113-22.

28. Arusula SY\& WHC. Pembentukan Mawas Demam Berdarah (DBD) Terhadap Angka Bebas Jentik (ABJ). 2017;5(1):1-9.

29. Pratamawati D. Peran Juru Pantau 
Jentik dalam Sistem Kewaspadaan Dini Demam Berdarah Dengue di Indonesia. Kesmas Natl Public Heal J. 2012;6:243.

30. Osaghae EN, Okokpujie K, Ndujiuba C, Okesola O, Okokpujie IP. Epidemic alert system: A web-based grassroots model. Int $\mathrm{J}$ Electr Comput Eng. 2018;8(5):3809-28.

31. Prasti D, Winarno WW, Henderi. Analisis Kinerja Sistem Informasi Manajemen Universitas Cokroaminoto Palopo. J IIm Teknol Inf. 2018;8(1):9-20.

32. Yulianti N, Raharjo M, Sediyono E. Spatial-Based Information System for Early Precaution of Dengue Hemorrhagic Fever. Int J English Lit Soc Sci. 2019;4(5):1315-8.

33. Dom NC, Ahmad AH, Latif ZA, Ismail R. Integration of GIS-Based Model with Epidemiological data as a Tool for Dengue Surveillance. EnvironmentAsia. 2014;10(2):136-46. 